\title{
Computed Tomography is Useful for Preoperative Workup of Gastric Rupture Caused by Blunt Trauma
}

\author{
Kazuaki Takabe ${ }^{1}$ and Katsuyoshi Hatakeyama ${ }^{2}$ \\ ${ }^{1}$ Division of Surgical Oncology, Department of Surgery, Virginia Commonwealth University School of Medicine, West Hospital 7-402, \\ 1200 East Broad Street, P.O. Box 980011, Richmond, VA 23298-0011, USA \\ ${ }^{2}$ Department of Surgery, Niigata University, Niigata, Japan
}

Key words Gastric Rupture $\cdot$ Blunt trauma $\cdot$ Computed tomography $\cdot$ Diagnosis, Diagnostic peritoneal lavage

We read with interest the article by Ishikawa et al. on gastric rupture that appeared in a recent issue of the Journal. ${ }^{1}$ While this article is concise and well illustrated, we would like to make the following comments.

Ishikawa described a case that developed multiple ruptures of the stomach after blunt trauma, and reviewed its management. ${ }^{1}$ I cannot agree more with the authors to stress the usefulness of computed tomography (CT) on this entity, as we did in our previous report. ${ }^{2} \mathrm{We}$ emphasized that CT is particularly useful for assessing locations of associated injuries to multiple solid organs and vessels, and for detecting small amounts of free air. However, during the peer review process that took place in 1998, we encountered a fair amount of criticism by American trauma surgeons on obtaining CT in such patients. They considered diagnostic peritoneal lavage (DPL) to be the standard workup for patients with blunt abdominal trauma. Although DPL has never been the "standard of care" in Japan, the Journal is internationally distributed and we believe it is necessary to discuss the "world standard of care" within the Journal.

There has been a controversy regarding the use of CT vs DPL in the evaluation of blunt abdominal trauma. Multiple large-scale prospective studies done in the past criticized CT as an expensive, time-consuming study that has the potential to miss hollow viscus injuries. ${ }^{3}$
Thus, DPL is still regarded by some institutions in the United States to be the standard screening test for intraabdominal injuries. Recently, the situation has been changing due to the rapid advance in CT technology, which enables fast and sensitive diagnosis, ${ }^{4}$ and DPL is criticized for being an overly sensitive and invasive diagnostic tool. ${ }^{5}$ Therefore, the current consensus is trending toward reserving DPL only for the hemodynamically unstable patient, who does not allow time for CT.

Computed tomography was helpful by visualizing stomach dilatation and free air, and detecting splenic injury in the case of Ishikawa et al., ${ }^{1}$ and it helped us prepare for the associated injury to the superior mesenteric artery prior to surgery in our case. ${ }^{2}$ Therefore, we believe that $\mathrm{CT}$ is useful for the preoperative workup of gastric rupture caused by blunt trauma.

\section{References}

1. Ishikawa K, Ueda Y, Sonoda K, Yamamoto A, Hisadome T. Multiple gastric ruptures caused by blunt abdominal trauma: report of a case. Surg Today 2002;32:1000-3.

2. Takabe K, Ohtani T, Muto I, Takano Y, Miyauchi T, Kato H, et al. Computed tomography (CT) findings of gastric rupture after blunt trauma. Hepatogastroenterology 2000;47:901-3.

3. Meyer DM, Thal ER, Weigelt JA, Redman HC. Evaluation of computed tomography and diagnostic peritoneal lavage in blunt abdominal trauma. J Trauma 1989;29:1168-70; discussion 1170-2.

4. Pal JD, Victorino GP. Defining the role of computed tomography in blunt abdominal trauma: use in the hemodynamically stable patient with a depressed level of consciousness. Arch Surg 2002;137:1029-32; discussion 1032-3.

5. Drost TF, Rosemurgy AS, Kearney RE, Roberts P. Diagnostic peritoneal lavage. Limited indications due to evolving concepts in trauma care. Am Surg 1991;57:126-8. 